\title{
Sistem Penunjang Keputusan Pemilihan Paket IndiHome Calon Pelanggan Menggunakan Metode Weighted Product
}

\author{
Nadafi'ah Hari Fitri*, Agus Sidiq Purnomo** \\ *,** Program Studi Informatika, Fakultas Teknologi Informasi, Universitas Mercu Buana Yogyakarta, J1. Wates Km. 10 \\ Yogyakarta 55753, Indonesia \\ "nadafiahofficial@gmail.com, ${ }^{* *}$ sidiq@mercubuana-yogya.ac.id
}

\begin{abstract}
PT Telekomunikasi Indonesia is one of big companies in Indonesia that focuses on technology field. PT Telekomunikasi Indonesia has an important role in providing internet access, of which product is IndiHome. There are several types of internet package to provide the internet access offered by PT Telekomunikasi Indonesia.

In this research, the writer aims to help prospective customers make the best decision. Thus, the writer divides the prototype of Decision Support System for Choosing IndiHome Package for Prospective Customers Using WP Method in 4 (four) variables, namely speed, price, internet quota, and need.

Based on the results of the test conducted with 48 data using both manual and system calculation, there are 42 compatible data with a percentage of $87,5 \%$.
\end{abstract}

Keyword: Decision Support System; WP; IndiHome; Internet Package

\section{Introduction}

Produk IndiHome memberikan kemudahan dalam mengakses internet dengan kecepatan, biaya, kuota dan kebutuhan yang berbeda-beda hal ini membuat PT. Telekomunikasi Indonesia mempunyai kendala dalam menyediakan pilihan kepada calon pelanggan IndiHome untuk memutuskan pemilihan paket layanan IndiHome yang diinginkan oleh calon pelanggannya. Saat ini calon pelanggan dihadapkan pada berbagai pilihan paket internet dari IndiHome. Dengan adanya berbagai pilihan paket ini calon pelanggan dituntut untuk jeli dalam memilih paket internet yang sesuai dengan kebutuhan dan daya belinya. Hal ini tentunya akan mempersulit para calon pelanggan dalam menentukan pilihan yang tepat, sesuai dengan kriteria yang diinginkannya. Untuk mengatasi masalah tersebut maka akan dibuat suatu prototipe pendukung keputusan menggunakan metode WP (Weighted Product) yang diharapkan dapat membantu pengguna dalam menentukan pilihan paket internet yang sesuai kebutuhan.

IndiHome adalah layanan digital yang menyediakan Internet Rumah, Telepon Rumah dan TV Interaktif (IndiHome TV) dengan beragam pilihan paket. Saat ini, jaringan IndiHome sudah tersebar di seluruh wilayah Indonesia, dan terus berinovasi untuk memenuhi kebutuhan internet yang lebih baik bagi masyarakat [1]

Metode WP adalah metode untuk mengevaluasi beberapa alternatif dari satu set atribut atau kriteria, dengan setiap atribut satu dengan atribut lainnya. Metode WP menggunakan teknik multiplikasi untuk atribut peringkat atribut, dengan peringkat setiap atribut harus terlebih dahulu sesuai dengan bobot atribut. Proses ini mirip dengan proses normalisasi [2] [3].

Beberapa penelitian sebelumnya yang dijadikan sebagai rujukan antara lain penelitian mengenai pemilihan paket internet menggunakan Metode SMART (Simple Multi-Attribute Rating Technique) dan Metode WP [4], serta Metode ANP [5] yang digunakan untuk membantu masyarakat dalam menentukan alternatif yang akan dipilih sebagai keputusan dalam pemilihan paket internet sesuai kebutuhan. Dari hasil pengujian sistem ini diperoleh hasil yang sama untuk paket dengan kuota 1.8GB-2GB.

Selanjutnya penelitian mengenai pemilihan pegawai, pada penelitian ini digunakan 4 kriteria (kehadiran, kecepatan kerja, tanggung jawab, dan kerja sama), yang selanjutnya dilakukan optimalisasi menggunakan Fuzzy Multiple Attribute Decision Making (FMADM) dan WP. Penilaian pegawai terbaik dilakukan menggunakan empat kriteria yaitu, kehadiran, kecepatan kerja, tanggung jawab, dan kerja sama. 2.Hasil perhitungan tertinggi menggunakan sistem yaitu 0.0782 [6].

Selanjutnya dalam penelitian pemilihan guru terbaik di MAN 1 Pariaman, pada penelitian ini dikembangkan sistem pendukung keputusan dengan mencari nilai bobot untuk setiap atribut dengan cara memberikan tim penilai kuesioner. Setelah itu dilakukan proses perangkingan yang menentukan alternatif optimal dengan WP. Hasil dari penelitian ini adalah mengahasilkan laporan perangkingan yang menampilkan guru terbaik [7]. 


\section{Research Method}

Dalam melakukan penelitian diperlukan data-data yang dibutuhkan yaitu, data mekanisme pelaksanaan pemilihan paket IndiHome calon pelanggan yang diperoleh dengan melakukan wawancara dan observasi di PT. Telekomunikasi Indonesia Regional Yogyakarta. Kedua data calon pelanggan yang diambil dengan memberikan kuesioner dari bulan Mei hingga Juni pada tahun 2020. Selanjutnya data bobot setiap kriteria paket IndiHome yang dipilih oleh calon pelanggan. Tahap metodologi yang dilakukan seperti pada Gambar 1.

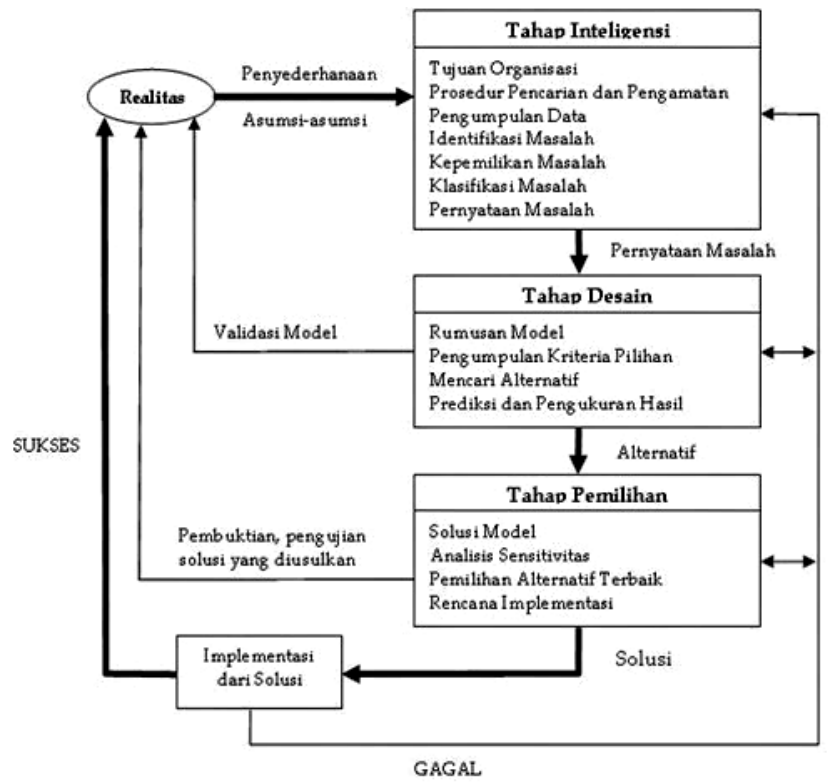

Gambar 1. Tahap Metodologi Penelitian [8]

Dalam melakukan pemilihan paket IndiHome calon pelanggan memerlukan empat (4) bobot kriteria yang harus diisi, antara lain Kriteria kecepatan (C1) pada Tabel 1, criteria kebutuha (C2) pada Tabel 2, kriteria FUP (Fair Usag Policy) / kuota (C3) pada Tabel 3, Analisis kriteria harga (C4) pada Tabel 4.

Tabel 1. Kriteria Kecepatan (C1)

\begin{tabular}{llll}
\hline Kriteria & Kecepatan & Nilai & Keterangan \\
\hline & $10 \mathrm{Mbps}$ & 1 & Paling Kecil \\
& $20 \mathrm{Mbps}$ & 2 & Sangat Kecil \\
$30 \mathrm{Mbps}$ & 3 & Kecil \\
Kecepatan & $40 \mathrm{Mbps}$ & 4 & Sedang \\
& $50 \mathrm{Mbps}$ & 5 & Sedikit Cepat \\
& $100 \mathrm{Mbps}$ & 6 & Cepat \\
& $200 \mathrm{Mbps}$ & 7 & Sangat Cepat \\
& $300 \mathrm{Mbps}$ & 8 & Maksimal \\
\hline
\end{tabular}

Tabel 2. Kriteria Kebutuhan (C2)

\begin{tabular}{llll}
\hline Kriteria & Kebutuhan & Nilai & Keterangan \\
\hline \multirow{3}{*}{ Kebutuhan } & 1 Jenis & 1 & Sangat Sedikit \\
& 2 Jenis & 2 & Sedikit \\
& 3 Jenis & 3 & Sedang \\
4 Jenis & 4 & Banyak \\
5 Jenis & 5 & Sangat Banyak \\
\hline
\end{tabular}

Tabel 3. Kriteria FUP (Fair Usage Policy) (C3)

\begin{tabular}{llll}
\hline Krieria & FUP & Nilai & Keterangan \\
\hline & $300 \mathrm{~Gb}$ & 1 & Sangat Kecil \\
FUP/Kuota & $500 \mathrm{~Gb}$ & 2 & Kecil \\
& $700 \mathrm{~Gb}$ & 3 & Sedang \\
& $900 \mathrm{~Gb}$ & 4 & Besar \\
& $1200 \mathrm{~Gb}$ & 5 & Sangat Besar \\
\hline
\end{tabular}


Tabel 4. Kriteria kriteria harga (C4)

\begin{tabular}{llll}
\hline Kriteria & Harga & Nilai & Keterangan \\
\hline & $<$ Rp200.000 & 1 & Sangat Murah \\
Harga & $>\operatorname{Rp} 200.000,<\operatorname{Rp} 300.000$ & 2 & Murah \\
& $>\operatorname{Rp} 300.000,<\operatorname{Rp} 400.000$ & 3 & Sedang \\
& $>\operatorname{Rp} 400.000,<\operatorname{Rp} 700.000$ & 4 & Mahal \\
& $>\operatorname{Rp} 700.000$ & 5 & Sangat Mahal \\
\hline
\end{tabular}

Kemudian mencari bobot ternormalisasi dengan bobot ternormalisasi $=$ bobot setiap kriterian/penjumlahan semua bobot kriteria. Berikut adalah perbandingan criteria dan kecepatan pada Tabel 5 .

Tabel 5. Alternatif per Kriteria

\begin{tabular}{|c|c|c|c|c|}
\hline \multirow[t]{2}{*}{ Alternatif } & \multicolumn{4}{|c|}{ Kriteria } \\
\hline & C1 & $\mathrm{C2}$ & $\mathrm{C3}$ & $\mathrm{C4}$ \\
\hline A1 & 1 & 2 & 1 & 4 \\
\hline A2 & 2 & 2 & 2 & 4 \\
\hline A3 & 5 & 4 & 5 & 5 \\
\hline A4 & 6 & 4 & 6 & 5 \\
\hline A5 & 7 & 4 & 5 & 5 \\
\hline A6 & 8 & 4 & 6 & 5 \\
\hline A7 & 1 & 2 & 1 & 3 \\
\hline A8 & 2 & 2 & 2 & 3 \\
\hline A9 & 3 & 2 & 2 & 4 \\
\hline A10 & 4 & 2 & 4 & 4 \\
\hline A11 & 5 & 2 & 5 & 4 \\
\hline A12 & 1 & 1 & 1 & 3 \\
\hline A13 & 2 & 1 & 2 & 3 \\
\hline A14 & 5 & 1 & 5 & 4 \\
\hline A15 & 6 & 1 & 6 & 5 \\
\hline A16 & 1 & 1 & 1 & 2 \\
\hline A17 & 2 & 1 & 2 & 3 \\
\hline A18 & 5 & 1 & 5 & 4 \\
\hline A19 & 6 & 1 & 6 & 5 \\
\hline A20 & 1 & 2 & 1 & 1 \\
\hline A21 & 1 & 3 & 1 & 1 \\
\hline A22 & 1 & 2 & 1 & 3 \\
\hline A23 & 2 & 2 & 2 & 3 \\
\hline A24 & 5 & 2 & 5 & 4 \\
\hline A25 & 1 & 3 & 1 & 3 \\
\hline A26 & 2 & 3 & 2 & 4 \\
\hline A27 & 3 & 3 & 3 & 4 \\
\hline A28 & 4 & 3 & 2 & 5 \\
\hline A29 & 5 & 1 & 5 & 5 \\
\hline A30 & 6 & 1 & 6 & 5 \\
\hline A31 & 1 & 3 & 1 & 3 \\
\hline A32 & 2 & 3 & 2 & 4 \\
\hline A33 & 3 & 3 & 3 & 4 \\
\hline
\end{tabular}

Pengambil keputusan memberikan bobot pada masing-masing kriteria berdasarkan sebagai berikut contoh data ke-9:

Vektor bobot : $\mathrm{W}=[6,3,6,2]$

$$
\begin{aligned}
& r_{1} \frac{6}{(6+3+6+2)}=\frac{6}{17}=0,353 \\
& r_{2} \frac{3}{(6+3+6+2)}=\frac{3}{17}=0,176
\end{aligned}
$$




$$
\begin{aligned}
& r_{3} \frac{6}{(6+3+6+2)}=\frac{6}{17}=0,353 \\
& r_{4} \frac{2}{(6+3+6+2)}=\frac{2}{17}=0,118
\end{aligned}
$$

Menghitung vektor (S) dengan mengalikan seluruh kriteria setiap sebuah alternatif dengan bobot sebagai pangkat positif untuk kriteria benefit dan bobot berfungsi sebagai pangkat negatif pada kriteria cost dapat dilihat sebagai berikut:

$$
\begin{aligned}
& S_{1}=\left(\left(1^{0,353}\right) *\left(2^{0,176}\right) *\left(1^{0,353}\right) *\left(4^{-0,118}\right)\right)=0,96 \\
& S_{33}=\left(\left(3^{0,353}\right) *\left(3^{0,176}\right) *\left(3^{0,353}\right) *\left(4^{-0,118}\right)\right)=2,24
\end{aligned}
$$

Total dari jumlah vektor (S) adalah 68,722

Melakukan perhitungan untuk mengetahui nilai vektor (V) yaitu yang digunakan untuk perangkingan, hasil dari menghitung nilai preferensi dari setiap alternatif dengan cara membagi vektor (S) dengan total vektor $(\mathrm{S})$

$$
\begin{aligned}
& V_{1}=(0,960 / 68,722)=0,139 \\
& V_{33}=(2,240 / 68,722)=0,033
\end{aligned}
$$

Hasil perangkingan diperoleh seperti di atas, nilai terbesar ada pada V6 yaitu 0,060 dengan demikian alternatif V6 adalah alternatif terbaik.

Perancangan Data Flow Diagram untuk level konteks diagram dalam penelitian ini dapat dilihat pada Gambar 2.

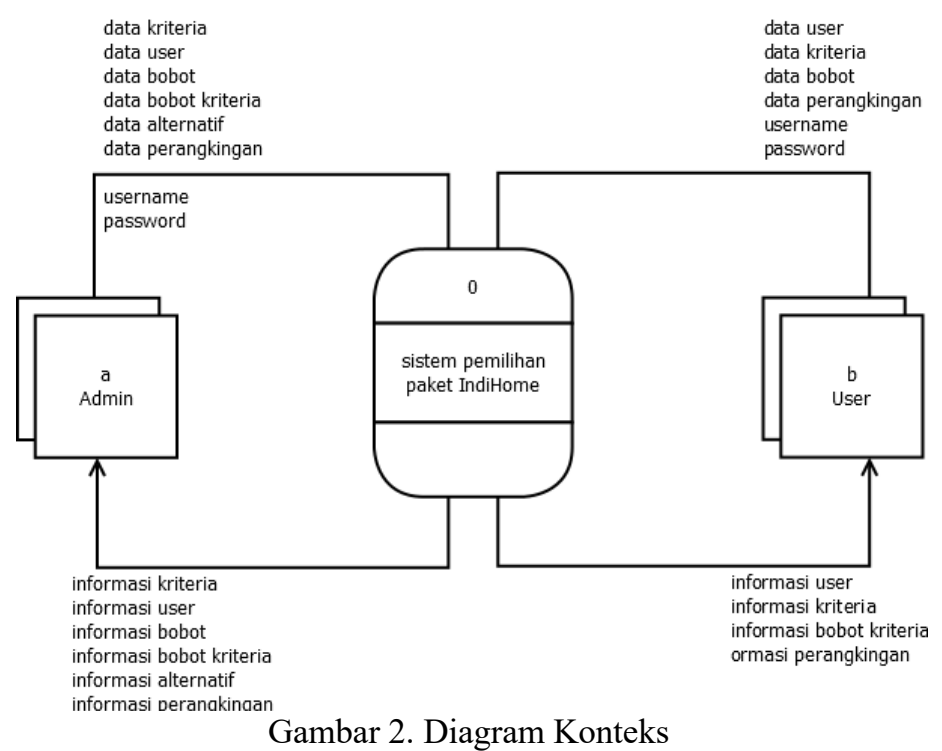

Rancangan Entity Relational Diagram dan relasi tabel yang digunakan dalam penelitian ini dapat dilihat pada Gambar 3 dan Gambar 4.. 


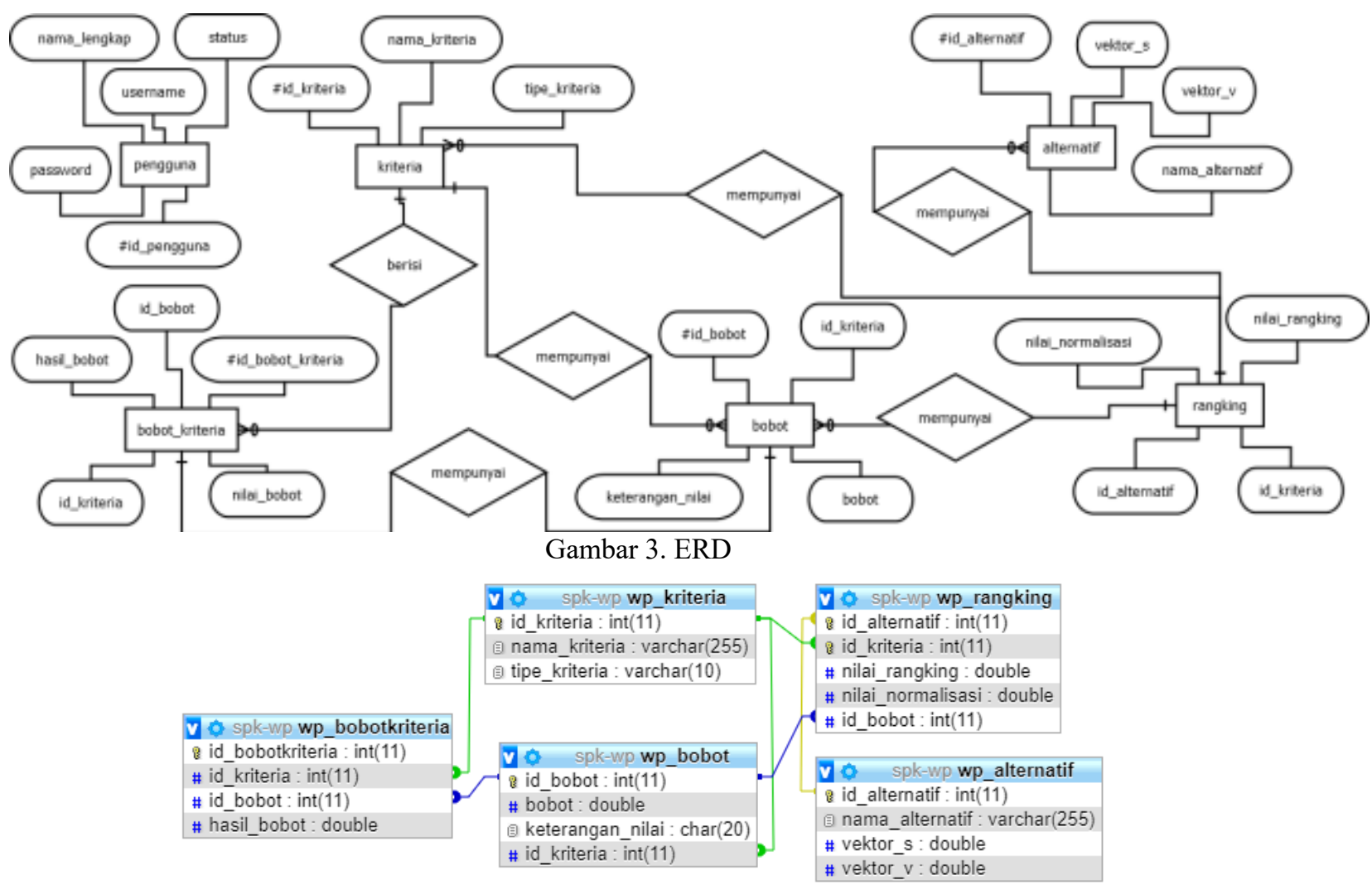

\section{Result and Analysis}

Hasil dari penelitian dengan membandingkan perhitungan perangkingan metode manual dengan perangkingan dengan sistem dapat dilihat pada Gambar 5.

\begin{tabular}{|c|c|c|c|c|c|c|}
\hline UHat SEMLA Datia & wasngan & & & & & \\
\hline \multicolumn{7}{|l|}{ Perangkingan } \\
\hline \multicolumn{5}{|l|}{ Show $50 \quad \sim$ entries } & \multicolumn{2}{|c|}{ Search: } \\
\hline \multirow{2}{*}{ Alternatif } & \multicolumn{4}{|c|}{ Kriteria } & \multirow{2}{*}{ Vektor $\mathrm{S}$} & \multirow{2}{*}{ Vektor $\mathrm{V}$} \\
\hline & Kecepatan & Kebutuhan & FUP/Kuota & Harga & & \\
\hline Prestige 300 Mbps & 2.0832320213012 & 1.2771616839561 & 1.8820953329761 & 0.82750044269107 & 4.143748379002923 & 0.060296914889027 \\
\hline Prestige 100 Mbps & 1.8820953329761 & 1.2771616839561 & 1.8820953329761 & 0.82750044269107 & 3.7436682066155154 & 0.054475229328806 \\
\hline Prestige 200 Mbps & 1.9873295787194 & 1.2771616839561 & 1.7647091895224 & 0.82750044269107 & 3.706630608564036 & 0.053936284225691 \\
\hline Prestige 50 Mbps & 1.7647991895224 & 1.2771616839561 & 1.7647991895224 & 0.82750044269107 & 3.291582213589318 & 0.047896791607503 \\
\hline FT 50 Mbps & 1.7647991895224 & 1.1301157834293 & 1.7647991895224 & 0.8495117942177 & 2.9900809391298955 & 0.043509556905431 \\
\hline Rumsh Ceria 50 Mbps & 1.7647991895224 & 1.1301157834293 & 1.7647991895224 & 0.8495117942177 & 2.9900809391298955 & 0.043509556905431 \\
\hline Streamix $100 \mathrm{Mbps}$ & 1.8820953329761 & 1 & 1.8820953329761 & 0.82750044269107 & 2.931240620231602 & 0.042653353927801 \\
\hline Phoenix 100 Mbps & 1.8820953329761 & 1 & 1.8820953329761 & 0.82750044269107 & 2.931240620231602 & 0.042653353927801 \\
\hline Gamer 100 Mbps & 1.8820953329761 & 1 & 1.8820953329761 & 0.82750044209107 & 2.931240020231002 & 0.042053353927801 \\
\hline Streamix 50 Mbps & 1.7647991895224 & 1 & 1.7647991895224 & 0.8495117942177 & 2.645818227630202 & 0.038500087817023 \\
\hline Phoenix 50 Mbps & 1.7647091895224 & 1 & 1.7647991895224 & 0.8495117942177 & 2.645818227630262 & 0.038500097817023 \\
\hline Gamer S0 Mbps & 1.7647991805224 & 1 & 1.7647901805224 & 0.82750044269107 & 2.577263517171456 & 0.037502527839027 \\
\hline
\end{tabular}




\begin{tabular}{|c|c|c|c|c|c|c|}
\hline FाT 40 Mbps & 1.6311419669656 & 1.1301157834293 & 1.6311419669656 & 0.8495117942177 & 2.5543233679122603 & 0.037168718905446 \\
\hline Gamer 30 Mbps & 1.4736547115524 & 1.2139418073171 & 1.4736547115524 & 0.8495117942177 & 2.2395396466767754 & 0.032589207370536 \\
\hline BCs 30 Mbps & 1.4736547115524 & 1.2139418073171 & 1.4736547115524 & 0.8495117942177 & 22395396466767754 & 0.032588207370536 \\
\hline Gamer $40 \mathrm{Mbps}$ & 1.6311419669656 & 1.2139418073171 & 1.2771616839561 & 0.82750044269107 & 20926844427683005 & 0.030451273628143 \\
\hline FाT 30 Mbps & 1.4736547115524 & 1.1301157834293 & 1.2771616839561 & 0.8495117942177 & 1.806899388768527 & 0.026292730323511 \\
\hline Gamer $20 \mathrm{Mbps}$ & 1.2771616839561 & 1.2139418073171 & 1.2771616839561 & 0.8495117942177 & 1.682128011415182 & 0.024477144908387 \\
\hline BCS 20 Mbps & 1.2771616839561 & 1.2139418073171 & 1.2771616839561 & 0.8495117942177 & 1.682128011415182 & 0.024477144908387 \\
\hline Fा $20 \mathrm{Mbps}$ & 1.2771616839561 & 1.1301157834293 & 1.2771616839561 & 0.87875556365458 & 1.619879799879143 & 0.02357135267158 \\
\hline Rumah Ceria 20 Mbps & 1.2771616839561 & 1.1301157834293 & 1.2771616839561 & 0.87875556365458 & 1.619879799879143 & 0.02357135267158 \\
\hline Prestige 20 Mbps & 1.2771616839561 & 1.1301157834293 & 1.2771616839561 & 0.8495117942177 & 1.5659724411750726 & 0.02278693066465 \\
\hline Streamix 20 Mbps & 1.2771616839561 & 1 & 1.2771616839561 & 0.87875556365458 & 1.4333750785814794 & 0.020857467011082 \\
\hline Phoenix 20 Mbps & 1.2771616839561 & 1 & 1.2771616839561 & 0.87875556365458 & 1.4333750785814794 & 0.020857467011082 \\
\hline LFH 3P & 1 & 1.2139418073171 & 1 & 1 & 1.2139418073171 & 0.017664428228058 \\
\hline LFH 2P & 1 & 1.1301157834293 & 1 & 1 & 1.1301157834293 & 0.016444650827128 \\
\hline Gamer 10 Mbps & 1 & 1.2139418073171 & 1 & 0.87875550365458 & 1.0667581171327978 & 0.015522714584183 \\
\hline BCS 10 Mbps & 1 & 1.2139418073171 & 1 & 0.87875556365458 & 1.0607581171327978 & 0.015522714584183 \\
\hline FT 10 Mbps & 1 & 1.1301157834293 & 1 & 0.87875550365458 & 0.9930955322623518 & 0.014450828406696 \\
\hline
\end{tabular}

Gambar 5. Hasil Pembahasan

Untuk mencari jumlah persentase keberhasilan dpat menggunakan rumus sebagai berikut :

$\%=$ (jumlah keberhasilan/jumlah keseluruhan) $\times 100 \%$

$=(42 / 48) \times 100 \%$

$=87,5 \%$ $87,5 \%$.

Maka, dapat diambil kesimpulan jumlah persentase keberhasilan yang diperoleh pada sistem bernilai

\section{Conclusion}

Berdasarkan hasil penelitian maka dapat disimpulkan, dalam pelaksanaan penelitian pemilihan paket IndiHome pada calon pelanggan ini diperlukan empat (4) kriteria yaitu kecepatan, kebutuhan, FUP (Fair Usage Policy) dan harga dengan nilai skala yang berbeda-beda dikarenakan setiap kriteria mempunyai nilainya masing-masing. Oleh karena itu perlu diperhatikan pada pemberian nilai sesuai dengan skala kriterianya. Yang kedua prosentase dengan membandingkan hasil perhitungan sistem dengan rekomendasi dari PT. Telekomunikasi Indonesia menggunakan perhitungan manual dengan kondisi yang berjalan berdasarkan 48 data yang telah diujikan, diperoleh sebanyak 48 data rekomendasi $(87,5 \%)$ yang sesuai.

\section{References}

[1] P. T. I. Telkom, "www.indihome.co.id/pusat-bantuan," 2019. [Online]. Available: https://www.indihome.co.id/ pusat-bantuan/ kenali-indihome/ apa-itu-indihome. [Accessed 01 Maret 2020].

[2] E. Sundari, S. K, P. Deepalakshmi, F. R. Irviani, N. Aminudin and A. Maseleno, "Weighted Product and Its Application to Measure Employee Performance," International Journal of Engineering \& Technology, 2018.

[3] S. Kusumadewi and H. Purnomo, Aplikasi Logika Fuzzy Untuk Pendukung Keputusan, Yogyakarta: Graha Ilmu, 2013.

[4] F. A. Hasyim, "Implementasi Metode SMART (Simple Multi Attribute Rating Technique) dan Metode WP (Weighted Product) pada Sistem Pendukung Keputusan dalam Menentukan Paket Internet," 2016.

[5] A. H. Azhar and R. A. Destari, "Optimasi Desicion Support System (DSS) Pemilihan Paket Layan Internet Prabayar dengan Metode ANP," Jurnal Sains Komputer \& Informatika (J-SAKTI), 2019.

[6] M. R. N. Septian and A. S. Purnomo, "Sistem Penilaian Pegawai Menggunakan Metode Fuzzy Multiple Attribute Decision Making (FMADM) dan Weighted Product (WP)," JMAI (Jurnal Multimedia \& Artificial Intelligence), Vol. 1, No. 1, ISSN : 2580-2593, pp. 27-33, 2017.

[7] A. T. A. Sundara, I. Stephane and M. Fadli, "Sistem Penunjang Keputusan Guru Terbaik dengan Metode Weight Product pada MAN 1 Pariaman," Jurnal Informatika, 2019.

[8] E. Turban, Decision Support System and Intelligent System (Sistem Pendukung Keputusan dan Sistem Cerdas), Yogyakarta: Andi Offset, 2005.

[9] N. Nurjannah, Z. Arifin and D. M. Khairina, "Sistem Pendukung Keputusan Pembelian Sepeda Motor Dengan Metode Weighted Product," Jurnal Informatika Mulawarman, 2015. 
[10] R. P. Utami, "Sistem Pendukung Keputusan Pemilihan Lokasi Pembangunan Perumahan dengan Metode AHP dan WP," 2019. 